\title{
Temporal adverbials, negation and finiteness in Dutch as a second language: A scope-based account
}

\author{
JOSJE VERHAGEN
}

\begin{abstract}
This study investigates the acquisition of post-verbal (temporal) adverbials and post-verbal negation in L2 Dutch. It is based on previous findings for L2 French that post-verbal negation poses less of a problem for L2 learners than postverbal adverbial placement (Hawkins et al. 1993; Herschensohn 1998). The current data show that, at first sight, Moroccan and Turkish learners of Dutch also have fewer problems with post-verbal negation than with post-verbal adverbials. However, when a distinction is made between different types of adverbials, it seems that this holds for adverbials of position such as 'today' but not for adverbials of contrast such as 'again'. To account for this difference, it is argued that different types of adverbial occupy different positions in the L2 data for reasons of scope marking. Moreover, the placement of adverbials such as 'again' interacts with the acquisition of finiteness marking (resulting in post-verbal placement), while there is no such interaction between adverbials such as 'today' and finiteness marking.
\end{abstract}

\section{Introduction}

Natural languages differ as to where they allow adverbials ${ }^{1}$ to be placed. On the one hand, there are languages in which adverbials precede the finite lexical verb such as English:

(1) John always goes to this shop.

On the other hand, there exist languages such as German and Dutch, in which finite lexical verbs are raised over adverbials, resulting in post-verbal adverbial

1. The term 'adverbial' instead of 'adverb' is used in this paper to include temporal expressions that contain more than one word such as 'last week' and 'the first time' under the definition. 
placement. This can be illustrated with the following Dutch sentence in which the temporal adverbial altijd 'always' follows the finite verb:

$$
\begin{aligned}
& \text { Jan gaat altijd naar deze winkel. } \\
& \text { John goes always to this shop } \\
& \text { 'John always goes to this shop'. }
\end{aligned}
$$

Further cross-linguistic differences arise when adverbials are placed in sentence-initial position. Whereas the subject can directly follow the fronted adverbial in English and French, it cannot in languages such as Dutch and German that are subject to the verb-second constraint. In verb-second languages, finite verbs must occur in second position in declarative main clauses and hence, the placement of an adverbial in initial position entails inversion of the subject and the finite verb:

$$
\begin{aligned}
& \text { Altijd gaat Jan naar deze winkel. } \\
& \text { always goes John to this shop } \\
& \text { 'Usually, John goes to this shop.' }
\end{aligned}
$$

For $\mathrm{L} 2$ acquisition, the question can be raised of how learners acquire the placement of adverbials in an L2 that has verb-raising. Meisel, Clahsen and Pienemann (1981), Clahsen, Meisel and Pienemann (1983), and Clahsen (1980) were among the first to shed light on this question in their early ZISA-studies on longitudinal data of Romance learners of German. The results of these studies show that learners initially place adverbials in sentence-initial or sentencefinal position, yet without applying subject-verb inversion in the case of sentence-initial adverbials. An example of such an early utterance is given in (4). Somewhat later in the acquisition process, Romance learners of German also start placing adverbials in sentence-medial position, as in (5).

$$
\begin{aligned}
& \text { Und die ende wochen meine familie suchen. } \\
& \text { and the end week my family visit }
\end{aligned}
$$

'And at the end of the week, my family will visit (me).'2

(Clahsen 1980: 64)

$$
\begin{aligned}
& \text { Die bringen jedes jahr ein wunderbares zeugnis. } \\
& \text { they bring every year a wonderful report } \\
& \text { 'Every year they bring a wonderful report.' (Clahsen 1980: 65) }
\end{aligned}
$$

2. All English translations in the paper are the author's: the original examples in Clahsen (1980), Becker (2005), Starren (2001) and Jordens and Dimroth (2006) only contained word-by-word glosses or literal translations. Hence, these authors are not to be held responsible for possible errors in the translations. 
Subject-verb inversion is also acquired at this stage but not immediately applied across the board, that is, sentences in which the subject and the verb are inverted co-occur with non-inverted sentences in the L2 data for some time. Similarly, the post-verbal placement of adverbials as in (5) alternates with preverbal adverbial placement in L2 learners' production. However, Meisel et al. (1981: 151-152) decided not to take this pre-verbal placement into account when establishing the above stages.

Eubank (1992: 32) also studied adverbial placement in longitudinal Romance-German and concluded that, in fact, 'every logically possible order of initial subjects, verbs and adverbials is present' including the pre-verbal placement of adverbials. Eubank left open the question, however, of whether there were functional differences between the various orders. Starren (2001) did look at such differences in a study on temporal adverbials in L2 Dutch and French. Starren's results indicate that L2 learners place adverbials in a certain position for reasons of scope-marking: temporal adverbials in sentence-initial position have the entire utterance in their scope, while temporal adverbials that occur adjacently to the verb are in focus position. According to Starren, L2 learners use sentence-initial adverbials to mark the time for which the entire utterance makes a claim, the so-called 'topic time': such sentences are possible answers to questions of the type 'what happened at time $t_{x}$ ? (Klein and Perdue 1997: 318). In contrast, temporal adverbials that are placed in the focus part of an utterance mark the time for which the event expressed by the predicate holds, the 'time of situation'. Sentences of this sort are possible answers to questions such as 'when did this happen?'

The idea that sentence-initial and sentence-medial adverbials have different scope properties in L2 acquisition is based on two findings. First, Starren found that Moroccan and Turkish learners Dutch sometimes produced utterances in which both positions were filled with an adverbial, such as (6) below. In this example, gisteren-jaar 'yesterday-year' occurs in topic position and marks the topic time, whereas altijd 'always' appears in focus position and marks the time of situation.

$$
\begin{aligned}
& \text { Gisteren-jaar ik altijd ongeluk gedaan. } \\
& \text { yesterday-year I always accident made } \\
& \text { 'Last year I had accidents, again and again.' (Starren 2001: 151) }
\end{aligned}
$$

Second, Starren observed that the adverbial altijd 'always' could express different aspectual notions in L2 acquisition, depending on its position in a sentence. When it occurred in initial position in learners' utterances, where it had scope over the entire utterance including the topic, it carried a habitual meaning. However, when it occurred in focus position, it had scope over the predicate only and expressed iterativity. The following examples from Moroccan learners of Dutch illustrate this: 
Altijd ik wakker om acht uur.

always I awake at eight o'clock

'I always wake up at eight o'clock.' (Starren 2001: 150)

$$
\begin{array}{lllll}
\text { Vandaag } & \text { ik } & \text { altijd } & \text { weg } & \text { met auto. } \\
\text { today } & \text { I } & \text { always } & \text { here-and-there with car }
\end{array}
$$

'Today I had to go away by car, again and again.' (Starren 2001: 151)

The claim that beginning learners place scope-bearing elements in a position right adjacent to the domain over which they have scope can also be found in studies on the acquisition of negation. Becker (2005) observed, for example, that Romance learners of German initially place the negator in front of the predicate of an utterance, since the predicate usually contains the semantic information of a sentence to which negation applies. Since predicates often contain lexical verbs, negation is typically pre-verbal in early L2 German:

$$
\begin{aligned}
& \text { Ich nich sprechen Deutsch gut. } \\
& \text { I not speak German well } \\
& \text { 'I don't speak good German.' (Becker 2005: 287) }
\end{aligned}
$$

The observation that beginning L2 learners use pre-verbal negation for reasons of scope marking receives support from a number of other studies involving L2 English and French (Giuliano 2003), L2 Italian (Bernini 2003), and L2 Dutch (Jordens and Dimroth 2006).

Adverbials and negation have two important properties in common. First, they occupy the same syntactic positions: both follow the finite verb when a language has verb-raising but precede the finite verb when a language does not allow verbs to be raised. Second, negation and (temporal) adverbials have scope properties: their placement interacts with the exact meaning they contribute to a sentence. Given these shared characteristics, one could predict that L2 learners acquire adverbial placement and negation placement in very much the same way.

There is empirical evidence, however, which shows that adverbials and negation do not develop on a par in L2 acquisition. Hawkins, Towell and Bazergui (1993) and Herschensohn (1998) found that English learners of French acquired the post-verbal placement of adverbials after the post-verbal placement of negation. The aim of the current study is to compare the acquisition of adverbial and negation placement in L2 Dutch. If it turns out that, in this language too, post-verbal adverbial placement is acquired later than post-verbal negation, this raises the question of how this should be explained.

Elicited production data are presented from Moroccan and Turkish learners of Dutch who were at a beginning level of acquisition. The results indicate that a distinction has to be made between different types of temporal adverbials: adverbials of position such as 'now' and 'today', on the one hand, and 
adverbials of contrast such as 'still' and 'again', on the other. The first type of adverbial, adverbials of position, specify time spans in relation to other time spans, which are supposed to be given in context (e.g., 'yesterday'). The second type of adverbial, adverbials of contrast, relate a time interval to another time interval, which is contextually implied (e.g., 'still' implies an earlier, adjacent time interval). The present data show that adverbials of position, when occurring sentence-medially, appear less often in post-verbal position than negation in L2 Dutch. Adverbials of contrast, however, are as often found in post-verbal position as negation. To account for this finding, it is proposed that there is a functional similarity between temporal adverbials of contrast and negation in L2 acquisition that does not apply to temporal adverbials of position and negation.

The paper proceeds as follows: the next section discusses the studies by Hawkins et al. (1992) and Herschensohn (1998) that showed that adverbial placement is acquired after negation placement in L2 French. Section 3 describes the relevant typological properties of the source and target languages under study. The study's methodology is described in Section 4 and the results are presented in Section 5. Finally, Section 6 and 7 discuss the results in light of the idea that different types of adverbials serve different functions in L2 acquisition.

\section{Adverbial and negation placement in $L 2$ acquisition}

To account for the placement of negation and adverbials in languages such as English and French, Pollock (1989) proposed that, at the level of D-structure, the same clause structure applies to both languages. However, a parametric difference in the realization of the functional category Agr brings about the placement differences at the surface level: verbs appear to the left of adverbials and negation in French but to the right of such elements in English. This parametric difference concerns the 'opacity' of English Agr versus the 'transparency' of French Agr. In English, Agr is 'weak' and opaque to the transmission of thetaroles. Consequently, lexical verbs cannot raise to Agr to Tense but affixes in Agr and T must lower onto such verbs. In contrast, strong 'Agr' in languages such as French permits verb-raising of lexical verbs: such verbs raise to Agr to Tense, thereby leaving behind adverbials and negation. In minimalism (Chomsky 1995), it has been proposed that the strength of features of the functional category INFL is related to verb-raising: verbs with strong features raise overtly to INFL for their features to be checked, while verbs with weak features do not raise.

In an acquisition study with English learners of French, Hawkins et al. (1993) investigated L2 learners' developing knowledge about the setting of the [ \pm opa- 
city] parameter. The authors presented 29 intermediate and 75 advanced English learners of French with a grammaticality judgment task that contained grammatical and ungrammatical sentences with souvent 'often' and pas 'not' of the types in (10a-10b) and (11a-11b). ${ }^{3}$ Apart from these sentences, the task also contained sentences with non-finite verbs and pas/souvent.

a. Ce journaliste interviewe souvent des syndicalistes.

b. *Ce journaliste souvent interviewe des syndicalistes.

'This journalist interviews often/*often interviews trades unionists.'

a. Puisqu'elle a beaucoup de travail en ce moment, Julie ne prend pas de vacances.

b. *Puisqu'elle a beaucoup de travail en ce moment, Julie ne pas prend de vacances.

'As she has a lot of work at the moment, Julie takes not/*not takes holiday.'

The results of the study showed that both the intermediate and advanced learners were highly accurate in judging the grammatical sentences with pas as being grammatical. However, the intermediate learners relatively often accepted incorrect adverbial placement: circa $40 \%$ of the learners judged sentences of type (10b) above as being grammatical. No such difference between negation and adverbial placement was found for the advanced learners.

The intermediate learners' differential behaviour for negation and adverbial placement is not expected if learners' task is to reset the Agr parameter from [+opaque] to [-opaque]. Rather than explain the results in terms of non-linguistic factors such as input frequency or pragmatic saliency, however, Hawkins et al. propose an account that is based on UG. More specifically, they propose that the intermediate learners' accurate judgements of pas placement results from a misanalysis of pas a verbal affix (following an account of negation proposed by Rizzi 1990). More precisely, when learners encounter pas to the right of lexical verbs in the input, they analyse it like a negator in languages such as Italian, in which a negation affix is generated under [+neg] Agr and taken along when Agr is lowered to T to V. Evidence for this idea comes from

3. Apart from investigating L2 learners' knowledge of pas and souvent placement, Hawkins et al. (1993) also looked at the placement of the floating quantifier tous 'all'. The results showed that the learners performed worse on sentences containing this quantifier than on sentences containing adverbials, suggesting the following development: pas placement $<$ souvent placement $<$ floated tous placement (Hawkins et al. 1993: 204). 
the finding that the intermediate learners also markedly accepted ungrammatical sentences of the type *Ne cherche pas-t-elle un remède dan l'acuponcture? ('Isn't she looking for a cure through acupuncture?) and *Ne voir pas son amie tous les jours est un supplice pour lui ('Not to see his girlfriend every day is torture for him'). According to the authors, this suggests that the intermediate learners of French found sentences grammatical in which pas is carried along with the verb, independent of the movement operation.

The finding that the intermediate learners relatively often accepted incorrect (pre-verbal) adverbial placement is also explained in terms of a UG-mechanism. More specifically, Hawkins et al. propose that the intermediate learners analysed adverbial placement in French as rightward adjunction of the complement to the VP: they wrongly assumed that the complement of the verb has to move to the right, across the adverb, in French. Under such an analysis, the underlying structure of sentence (10a) would be Ce journaliste interviewe des syndicalistes souvent and to arrive at the correct surface structure learners would move des syndicalistes over the adverbial souvent to post-verbal position.

On the basis of the different findings for negation and adverbial placement in the intermediate group, Hawkins et al. argue that these learners have not reset the [ \pm opacity] parameter. Instead, they use 'other devices made available by UG to mimic French surface patterns: misanalysis of pas as an affix generated under Agr, and rightward adjunction of verb complements over VP-final adverbs' (Hawkins et al. 1993: 219).

Using a different elicitation task, Herschensohn (1998) also found that adverbial placement is more difficult to acquire than negation placement for English learners of French. Herschensohn used a task in which learners were presented with a series of words and asked to form a sentence using these words. Unlike Hawkins et al., she presented more than one frequency adverbial (i.e., souvent 'often', rarement 'rarely', ne ... jamais 'never') as well as manner adverbials such as bien 'well'. The results showed a difference in accuracy between negation and adverbials in the intermediate learner group (but not the advanced group): $4 \%$ of the responses with adverbials were incorrect (pre-verbal placement) while no errors were found for negation. Although this difference seems rather small, Herschensohn concludes from these findings that 'negation is mastered before adverbial placement' (Herschensohn 1998: 330).

To explain her results, Herschensohn suggests parameter setting along constructionist lines: resetting a parameter is not an all-at-once phenomenon in L2 acquisition, but progressive learning, that takes place construction by construction. This means that learners have to acquire a substantial matter of vocabulary and morphology before they are able to set a given parameter to the L2 value. As long as L2 learners have not reset the parameter to the L2 value, they show variation that is bound to specific lexical items: pas is placed post- 
verbally earlier than jamais, ${ }^{4}$ negation placement is acquired before adverbial placement.

In short, the results presented in Hawkins et al. (1993) and Herschensohn (1998) show that English learners of French have more difficulties with adverbial placement than negation placement and conclude from this finding that adverbial placement follows negation placement in L2 acquisition. The explanation is either that learners apply different options provided by UG (Hawkins et al. 1993) or do not reset the parameter for all lexical items at once (Herschensohn 1998).

Both studies suffer from a number of methodological limitations, however. First, only English learners of French were considered which makes it impossible to rule out that adverbial placement is somehow more susceptible to L1 transfer than negation placement. Second, artificial language tasks were used in both studies (a written judgment task and a written sentence composition task). Such tasks assess meta-linguistic knowledge rather than natural production and therefore, different results might have been obtained when L2 data had been elicited that more closely reflect natural speech. Apart from these methodological issues, the explanations provided by Hawkins et al. and Herschensohn do not give satisfactory answers to a number of questions. Hawkins et al. do not explain, for example, why learners pick 'negation affixation' and 'rightward adjunction' from all options UG offers to them. Moreover, they leave unanswered the question of how learners eventually acquire the right UG mechanism: how and when do they replace negation affixation with verb-raising? As for Herschensohn's account, a description rather than an explanation of the results is provided, since it remains unclear why learners acquire the post-verbal placement of pas before jamais rather than vice versa.

In the current study, we compare the placement of temporal adverbials and negation in L2 Dutch. The point of departure is the idea that adverbials and negation have an important property in common in addition to their placement relative to the finite verb ${ }^{5}$, namely: scope marking. The data that are presented were elicited with production tasks (film-retelling and picture stories) and hence, allow for an investigation of relatively natural L2 data. Two groups of learners with (parametrically) different native languages - Moroccan Arabic and Turkish - participated so that possible L1-influence can be expected

4. One could argue, however, that jamais is a negator rather than an adverbial, in particular, because in French both pas and jamais are preceded by the negative element ne (e.g., Il ne vient jamais 'He never comes').

5. However, there are also differences between the positions negation and adverbials can occupy in Dutch: unlike adverbials, the negator cannot be fronted as a constituent or occur in sentence-final position. 
to show up in the data. More specifically, the following research questions were put forth:

1. Do Moroccan and Turkish learners of Dutch acquire verb-raising over negation before verb-raising over temporal adverbials?

2. If so, how can this be explained?

Before proceeding to the study proper, the following section addresses some general properties of temporal adverbials as well as the placement of adverbials and negation in Dutch, Moroccan Arabic and Turkish.

\section{Adverbials and negation in natural languages}

\subsection{Different types of temporal adverbials and scope marking}

Temporal adverbials are important for the expression of temporality. Or, as noted by Klein (1994: 143), 'the significance of temporal adverbials to the expression of temporality should be obvious: there are languages, which lack grammatical categories to express tense, but there is no language without temporal adverbials'. In fact, Klein argues that the expression of past tense might be considered redundant in sentences that also contain an adverbial referring to the past: adverbials such as 'yesterday' or 'two days ago' also mark that a situation is in the past and do so in a more detailed way than past tense marking on the verb.

Four types of adverbials are distinguished by Klein: temporal adverbials of position, temporal adverbials of frequency, temporal adverbials of duration, and temporal adverbials of contrast. The first of these, temporal adverbials of position (TAPs), ${ }^{6}$ specify time spans in relation to other time spans, which are supposed to be given in context, such as 'yesterday', 'now', and 'at five o'clock'. Temporal adverbials of frequency (TAFs) indicate the frequency of time spans. Examples are 'often', 'always', and 'twice'. The duration of time spans is specified by temporal adverbials of duration (TADs) such as 'briefly' and 'for an hour'. Finally, there is a fourth type of which the function is more complex: temporal adverbials of contrast (TACs) such as 'still', 'already', and 'again'. ${ }^{7}$ Members of this class indicate a comparison between the time interval referred to and another time interval, which is contextually implied. For example, in the sentence 'John is still sleeping' the adverbial 'still' expresses that in

6. These abbreviations are taken over from Starren and Van Hout (1996).

7. Klein's classification also includes two types of adverbial that will not be considered in the present paper: adverbials that denote inherent temporal properties of a situation such as 'quickly' and adverbials that indicate the position of a situation relative to another situation such as 'eventually' (Klein 1994: 149). 
addition to the current time interval ('topic time') at which John is sleeping, he was sleeping at an earlier, adjacent time interval.

An important characteristic of temporal adverbials is that they show an interaction between the position they occupy in a sentence and the time span(s) they specify. In other words, temporal adverbials have scope properties. As noted in the introduction, Starren (2001) notes that adverbials that are placed in initial position (in the topic component of an utterance) have scope over the tensed part of an utterance, the topic time. In contrast, when adverbials are placed in final (focus) position, close to the event specification itself, they have scope over the time of situation. Starren illustrates this with the following examples: ${ }^{8}$

$$
\begin{aligned}
& \text { a. On Monday, I'm working from } 2 \text { to } 5 \text {. } \\
& \text { b. I'm working on Monday from } 2 \text { to } 5 \text {. }
\end{aligned}
$$

'On Monday' in (12a) specifies a topic time: it could be an answer to the question 'What are your working hours on Monday?' and as such, expresses a contrast with possible other topic times such as 'on Wednesday' or 'on Tuesday'. In (12b), no such contrast is evoked because the topic time is not explicitly marked. This sentence could be an answer to the question 'When do you work?' Thus, fronted temporal adverbials narrow down the time span for which a claim is made, while temporal adverbials that are embedded in the utterances do not narrow down the topic time. ${ }^{9}$

\subsection{Dutch}

As was already pointed out in the introduction, finite verbs raise over negation and adverbials in Dutch declarative main clauses. This is illustrated in the examples in (13) and (14) that contain the negator niet 'not' and the temporal adverbial vandaag 'today', respectively.

(13) Hij werkt niet in Amsterdam.

he works not in Amsterdam

'He is not working in Amsterdam.'
Hij werkt vandaag in Amsterdam.
he works today in Amsterdam
'He is working in Amsterdam today.'

8. Originally, the verbs in these examples were in the present tense ('work') rather than in the present progressive. However, since this is not grammatical in English, the verb form was adapted for the current paper.

9. However, intonation may override these scope-marking relations: when 'on Monday' is stressed in sentence (12a), for example, its reading changes and comes close to that of (12b). 
Besides, temporal adverbials (but not negation) can occur in sentence-initial and sentence-final position. This can be seen from (15) and (16). ${ }^{10}$
Vandaag werkt hij in Amsterdam. today works he in Amsterdam 'Today he is working in Amsterdam.'
Hij werkt in Amsterdam vandaag.
he works in Amsterdam today
'He is working in Amsterdam today.'

\subsection{Moroccan Arabic and Turkish}

The native languages of the learners under study have different basic word orders. In Moroccan Arabic, both SVO and VSO are used. The language has verb-raising, but unlike in Dutch, the entire verb complex is raised in sentences that contain auxiliary verbs (Harrell 1962). Regarding the position of temporal adverbials, Holes (1995) notes that the sentence-initial position as well as the position after the verb complex are common. When adverbials appear at the sentence end, this is often an indication that they are taken up as the theme of the succeeding text. The following example illustrates the post-verbal placement of adverbials in Moroccan Arabic:

$$
\begin{aligned}
& \text { Ma ya } y \text {-kun-u-̌̌ } \quad \phi \quad m \check{s} a-w \quad d a b a \text {. } \\
& \text { Neg fut 3-be.imp-p-neg past leave.perf-3pl now } \\
& \text { 'They will not have left now/by now.' (Ouali and Fortin 2007: 11) }
\end{aligned}
$$

Moroccan Arabic marks negation by means of a split-morpheme containing the prefix $m a$ - and the suffix $-\check{s}$ that are both attached to the finite verb:

\section{Ma-ka-jakol-š.}

Neg-dur-eat-3sg.imp-neg

'He does not eat.' (Harrell 1962: 152)

10. These examples contain lexical verbs but the same applies to auxiliaries and modal verbs. 
Turkish has relatively strict SOV order and does not have verb-raising. ${ }^{11}$ The unmarked placement of adverbials is in between the subject and the object, as illustrated in (19).

$$
\begin{array}{llll}
\text { Ben } & \text { dün } & \text { Bebek-te Ali-ye rastla-dl-m. } \\
\text { I yesterday } & \text { Bebek-loc Ali-dat run into-past-1sg } \\
\text { 'I ran into Ali yesterday in Bebek.' (Erguvanlı 1984: 150) }
\end{array}
$$

Moreover, due to Turkish being a pro-drop language, adverbials also often appear in sentence-initial position in sentences where the subject is not overtly expressed. Negation is marked with the verbal suffix $-m a$, as can be seen in (20):

\author{
Hasan kitab-l oku-ma-dl. \\ Hasan book-acc read-neg-past \\ 'Hasan did not read the book.' (Kornfilt 1997: 123)
}

\title{
4. The study
}

\subsection{Learners}

A group of 55 Moroccan and 48 Turkish learners participated in the study. These learners were tested at schools where they took language courses that are compulsory for new immigrants in the Netherlands. All learners had reached level 1 or 2 out of 5 proficiency levels according to school tests and can thus be classified as beginning learners of Dutch. ${ }^{12}$ They received nine hours of teaching per week on average. The average length of residence in the Netherlands was $3: 8$ years for the Moroccan and $8: 1$ for the Turkish learners. All learners had a relatively low level of schooling: the majority had only been at primary

11. Ouhalla (1991) argued that the verb raises over -ma in Turkish, however, even though it does not raise over the negative element yok and the negative copula değil (examples are from Haznedar 1997: 246):

(i) Dün sizi ara-dl-m ama ev-de yok-tu-nuz

yesterday you call-past-1sg but house-dat not-exist-past-2sg

'I called you yesterday but you were not home.'

(ii) (Siz) bir yazar değil-di-niz.

you a writer not-past-2sg

'You were not a writer.'

12. These levels roughly correspond to the levels A1 and A2 as defined by the Council of Europe in the European Framework of Reference (2001). Thus, the current participants had a much lower level in the L2 than the learners that participated in Hawkins et al. (1993) and Herschensohn (1998). 
school, some learners had passed a few years at secondary school, and none of the learners had reached university level.

\subsection{Film-retelling task}

A film-retelling task involving a 15-minute fragment from the silent Modern Times movie (Charlie Chaplin) was presented to the learners. This movie has been used in a number of earlier studies on L2 acquisition, involving studies on temporal adverbials (Dietrich, Klein and Noyau 1995, Starren 2001). Unlike in this earlier work, the movie was cut into short fragments in the current study. Participants immediately retold what had happened in a fragment after having watched it so that more detailed and better comparable retellings could be obtained than when participants had to watch and retell the entire fragment in one go.

\subsection{Picture stories}

Apart from a film-retelling task, three picture stories were presented, that could be described by means of basic vocabulary. In order to increase the likelihood that participants would use temporal adverbials in their retellings, the stories were shown in two phases. First, participants looked at the entire story but were asked to not tell the story yet. Second, the stories were shown again and participants were now asked tell the corresponding story. By familiarizing participants with the story line before asking them to perform their retellings, it was hoped that they would use temporal adverbials in utterances like 'dog has now waken up', rather than give static descriptions of the type 'here is a dog', 'the dog is awake' in which temporal adverbials are less likely to occur.

\subsection{Coding and scoring}

First of all, all utterances containing a lexical verb and a temporal adverbial or the negator niet 'not' were extracted from the data. Subsequently, it was determined for each utterance whether the adverbial or negator preceded or followed the verb. Utterances that were likely to be rote-learned such as $I k$ weet niet 'I don't know' and Ik snap niet 'I don't understand', immediate repetitions and false starts were not considered. Importantly moreover, the analysis was restricted to sentences in which an overt subject was produced and the adverbial did not occur sentence-finally. The reason not to look at subject-less sentences was that it could not be determined for such sentences how the adverbial placement had to be analysed. More precisely, for an utterance Nu eten 


\section{Josje Verhagen}

alle taart 'Now eat all cake' in which the subject 'the dog' is not expressed, it is not clear whether the adverbial should be analysed as a fronted, sentenceinitial adverbial or as a sentence-medial adverb, preceding the verb. Likewise, for utterances with an adverbial in sentence-final position, it was impossible to tell whether the adverbial had been placed at the sentence-boundary (cf. the results from Clahsen 1980 described above) or whether it occurred behind the verb due to verb-raising. Therefore, such utterances were not taken into account either. For the sake of comparison, the same criteria were applied to negated sentences, resulting in the analysis of negated utterances with an overt subject and a negator in non-final position only. ${ }^{13}$

Having extracted all utterances from the data, it was made sure that the adverbials that occurred in these utterances actually had the status of adverbial. The word nog 'still/another', for example, is a temporal adverbial in a sentence like Hij slaapt nog 'He still sleeps' but a quantifier in a sentence like Hij neemt nog een bier 'He takes another beer'. Evidently, only sentences of the first type were considered for analysis. The frequently occurring expression en dan/en toen 'and then' was not included in the analysis, since it has been shown that Turkish learners use en dan as a discourse marker, that is, they use it to signal that they want to add something to their discourse (Dietrich et al. 1995).

\section{Results}

\subsection{Adverbial versus negation placement}

Table 1 presents how often learners placed temporal adverbials and the negator niet in pre- and post-verbal position with respect to the lexical verb.

Table 1. Pre- and post-verbal placement of adverbials and negation

\begin{tabular}{|c|c|c|c|c|c|c|c|c|c|c|}
\hline & \multicolumn{5}{|c|}{ Moroccan learners } & \multicolumn{5}{|c|}{ Turkish learners } \\
\hline & \multicolumn{2}{|c|}{ Pre-verbal } & \multicolumn{2}{|c|}{ Post-verbal } & \multirow[t]{2}{*}{ Total } & \multicolumn{2}{|c|}{ Pre-verbal } & \multicolumn{2}{|c|}{ Post-verbal } & \multirow[t]{2}{*}{ Total } \\
\hline & $\%$ & $\mathrm{~N}$ & $\%$ & $\mathrm{~N}$ & & $\%$ & $\mathrm{~N}$ & $\%$ & $\mathrm{~N}$ & \\
\hline Adverbials & 45 & $(21)$ & 55 & (26) & 47 & 71 & (58) & 29 & (24) & 82 \\
\hline Negation & 22 & (7) & 78 & (25) & 32 & 53 & (10) & 47 & (9) & 19 \\
\hline
\end{tabular}

13. Although it may not seem plausible that negation appears at the sentence-boundaries, Jordens and Dimroth (2006: 172) showed that L2 learners of Dutch may initially place 'holistic' negators at the sentence beginning or sentence end (e.g., Veel eten nee 'Much eat no'). 
It immediately appears that adverbials appear less often in post-verbal position than negation. The Moroccan learners place $55 \%$ of all temporal adverbials in post-verbal position versus $78 \%$ of all instances of niet. This difference is significant $\left(\chi^{2}(1)=4.328, p=.032\right)$, indicating that post-verbal negation is non-accidentally more frequent than post-verbal adverbial placement. In the data of the Turkish learners, $29 \%$ of all adverbials were placed post-verbally versus $47 \%$ of all instances of niet, but this difference does not reach significance $\left(\chi^{2}(1)=2.297, p=1.08\right)$. However, there is a clear tendency for negation to be placed more often in post-verbal position when compared to adverbials in this language group, too. The lack of an effect is therefore presumably due to the relatively low number of negated utterances in this group. ${ }^{14}$ Moreover, the data show that there is a general difference between the two language groups: while the Moroccan learners show an overall preference for post-verbal placement, the Turkish learners have a preference for pre-verbal placement, both with adverbials and negation. This difference turns out to be significant $\left(\chi^{2}(1)=8.542, p=.003\right)$, indicating that verb-raising over temporal adverbials is significantly less frequent than in the Moroccan group. However, when we take the results together, it appears that they are in line with the finding from Hawkins et al. (1993) and Herschensohn (1998) for L2 French that learners are more accurate in verb-raising over negation than over temporal adverbials.

\subsection{Different types of adverbials}

Temporal adverbials differ with respect to the specific time points or time spans they specify, as outlined in Section 3 above. Four types were distinguished in this section: temporal adverbials of position (TAPs), contrast (TACs), duration (TADs), and frequency (TAFs). Table 2 presents an overview of all adverbials that were found in the current data and classifies them according to type. As can be seen from the table, the learners mainly produced TAPs and TACs. The data of both learner groups were collapsed for the fact that no clear differences between the groups were observed.

Let us now look at how the two types of adverbial that were produced most often (TAPs and TACs) were distributed over post- and pre-verbal positions to see whether any differences could be found between these two types of adverbial. Table 3 shows how often the learners placed TAPs and TACs in pre- and

14. The low number of negated utterances was caused by the fact that the Turkish learners produced a high number of subjectless utterances. In fact, when all utterances containing negation were counted, including those with an overt subject and niet in final position, 162 negated utterances were produced in this language group. 
Table 2. Overview of all temporal adverbials in the data

\begin{tabular}{llc}
\hline & Adverbials & Total \\
\hline $\begin{array}{l}\text { Adverbials of } \\
\text { position (TAP) }\end{array}$ & $\begin{array}{l}\text { eerste keer 'first time', eerst 'at first', ineens 'at once', } \\
\text { laatst 'at last', nachten 'at night', nu 'now', straks } \\
\text { 'later' }\end{array}$ & 53 \\
$\begin{array}{l}\text { Adverbials of } \\
\text { contrast (TAC) }\end{array}$ & $\begin{array}{l}\text { 'ag/nog steeds 'still', nog een keer 'another time', weer } \\
\text { 'again', weer terug 'back again' }\end{array}$ & 64 \\
$\begin{array}{l}\text { Adverbials of } \\
\text { duration (TAD) }\end{array}$ & $\begin{array}{l}\text { tien dagen 'ten days', even 'just, shortly', gelijk 'imme- } \\
\text { diately' }\end{array}$ & 10 \\
$\begin{array}{l}\text { Adverbials of } \\
\text { frequency (TAF) }\end{array}$ & altijd 'always, soms 'sometimes' & 8 \\
\hline
\end{tabular}

Table 3. Pre- and post-verbal placement of TAPs, TACs, and negation

\begin{tabular}{|c|c|c|c|c|c|c|c|c|c|c|}
\hline & \multicolumn{5}{|c|}{ Moroccan learners } & \multicolumn{5}{|c|}{ Turkish learners } \\
\hline & \multicolumn{2}{|c|}{ Pre-verbal } & \multicolumn{2}{|c|}{ Post-verbal } & \multirow[t]{2}{*}{ Total } & \multicolumn{2}{|c|}{ Pre-verbal } & \multicolumn{2}{|c|}{ Post-verbal } & \multirow[t]{2}{*}{ Total } \\
\hline & $\%$ & $\mathrm{~N}$ & $\%$ & $\mathrm{~N}$ & & $\%$ & $\mathrm{~N}$ & $\%$ & $\mathrm{~N}$ & \\
\hline TAP & 80 & (12) & 20 & (3) & 15 & 79 & (30) & 21 & (8) & 38 \\
\hline TAC & 24 & (6) & 76 & (19) & 25 & 64 & (25) & 36 & (14) & 39 \\
\hline NEG & 22 & (7) & 78 & (25) & 32 & 53 & (10) & 47 & (9) & 19 \\
\hline
\end{tabular}

post-verbal position. It also contains the data for negation that were already presented above.

Focusing on the data from the Moroccan learners, a clear difference between both types of adverbials can be noted: TAPs predominantly occur in pre-verbal position, but TACs are more often found post-verbally. A chi-square test shows that this difference is significant $\left(\chi^{2}(1)=11.879, p=.001\right)$ : TACs occur significantly more often in post-verbal position than TAPs. Moreover, TACs and negation pattern remarkably alike in the data from the Moroccan learners $\left(\chi^{2}(1)=.036, p=.548\right)$. Taken together, the results of this group show predominant placement of TAPs in pre-verbal position, on the one hand, and predominant placement of TACs and negation in post-verbal position, on the other. These differences between TAPs and TACs/negation are highly significant $\left(\chi^{2}(1)=17.137, p=.000\right)$.

Considering the data from the Turkish learners, it appears that these learners also predominantly place TAPs in pre-verbal position. However, unlike the Moroccan learners who preferred TACs and negation in post-verbal position, 
the Turkish learners predominantly place TACs and the negator in pre-verbal position, even though they do so less often than in the case of TAPs. Indeed, it seems that the differences between TAPs and TACs do not reach significance $\left(\chi^{2}(1)=2.078, p=.117\right)$. However, if we compare the placement of TAPs, on the one hand, with the placement of TACs and negation, on the other, a significant difference is found $\left(\chi^{2}(1)=3.634, p=.045\right)$. Hence, even though the Turkish learners less frequently place TACs and negation in a postverbal position overall, the same difference can be observed between TAPs and TACs/negation: TAPs are more often placed in a pre-verbal position than TACs and negation.

The distributional difference between TAPs and TACs is illustrated in the utterances (21) to (24), all of which were produced by Moroccan learners. Notice that TAPs such as 'now' and 'at first' occur in pre-verbal position, whereas TACs such as 'still' and 'again' appear in post-verbal position.

$$
\begin{aligned}
& \text { Hij nu trekt de taart naar beneden. } \\
& \text { he now pulls the cake to down } \\
& \text { 'Now, he is pulling the cake down.' }
\end{aligned}
$$

$$
\begin{aligned}
& \text { Dit vrouw eerst kijk naar de winkel. } \\
& \text { this woman first look at the shop } \\
& \text { 'First, this woman is looking at the shop.' }
\end{aligned}
$$

$$
\begin{aligned}
& \text { Die bal staat nog op de boom. } \\
& \text { the ball stands still in the tree } \\
& \text { 'The ball is still hanging in the tree.' }
\end{aligned}
$$

$$
\begin{aligned}
& \text { Hij neem weer die trappen naar thuis. } \\
& \text { he take again the ladder to house } \\
& \text { 'He takes the ladder home again.' }
\end{aligned}
$$

\section{Explaining the different behavior of TAPs and TACs}

\subsection{Background: Finiteness in L2 Dutch}

In order to account for the differential behavior of TAPs on the one hand and TACs and negation on the other, let us consider a study by Jordens and Dimroth (2006) on the acquisition of finiteness by Moroccan and Turkish learners of Dutch. Since this study's outcomes are important for the interpretation of the current data, they are summarized below.

According to Jordens and Dimroth, L2 learners of Dutch who have not yet acquired finite verb marking produce sentences in which a topic and a predicate are juxtaposed, such as (25). 


$$
\begin{aligned}
& \text { Dan auto bijna vallen. } \\
& \text { then car nearly fall } \\
& \text { 'Then car nearly falls down.' (Jordens and Dimroth 2006: 177) }
\end{aligned}
$$

The topic dan auto 'then car' occurs in initial position and the predicate vallen 'fall' appears in final position. In this type of utterance, topics provide a temporal (or spatial) anchor-point for the rest of the utterance and therefore typically contain pronouns and temporal or deictic adverbials. The predicate expresses the information that is claimed to hold for the topic. Moreover, in (25) a socalled linking element occurs in between the topic and the predicate that asserts that the predicate is true of the topic. Often, these linking elements carry a meaning on their own such as bijna 'nearly' in the above example and thereby, such elements qualify the assertion in several ways. Importantly, the negator can also occur as a linking element and in such cases, it expresses 'negative assertion'. For an example, consider (26), in which niet 'not' expresses that the predicate goeje chauffeur is not true for the topic dames. Note furthermore from this example that predicates need not contain verbs at the present stage of acquisition. ${ }^{15}$

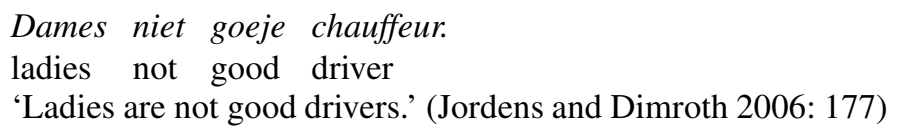

The examples that are provided by Jordens and Dimroth show that no fixed order applies to the elements that occur in the topic part of the utterance. That is, adverbials can precede or follow the subject pronoun or noun phrase. This is illustrated in the examples in (27) and (28) in which the adverbial altijd follows the subject pronoun but the adverbial nog drie maand precedes it. Note furthermore that in (27) the adverbial would have directly preceded the predicate in case the linking element wil 'want' had not been present.

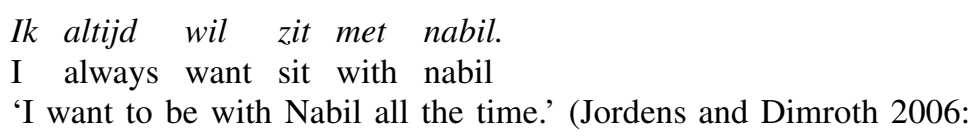

15. The fact that a form of the copula zijn 'be' is missing in this example is in line with findings from Becker (2005) who found that initially, there seems to be a complementary distribution in L2 German between the presence of a copula and negation such that negated sentences typically lack a copula while such a copula is present in these sentence's positive counterparts. Becker explains this by arguing that the copula initially marks (positive) assertion, rather than tense. 


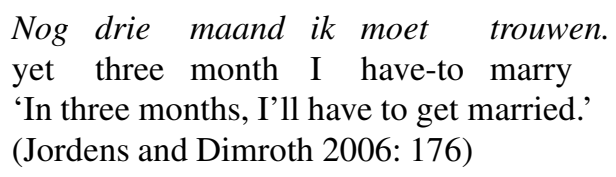

In both sentences, the temporal adverbial has scope over the entire utterance and marks the topic time or the time for which the utterance makes a claim (see Section 1). The modal verbs wil and moet in (27) and (28) are not yet considered instances of finite verbs at the current stags of acquisition by Jordens and Dimroth (2006). That is, they are not yet marked for finiteness but instead, consitute lexical, 'verb-like' elements that 'are not (yet) to be categorised as expressions of a verbal category' (Jordens and Dimroth 2006: 178).

According to Jordens and Dimroth, this basic system changes when L2 learners acquire finiteness marking. Namely, following Klein (1994), the authors argue that an important function of finiteness is to mark assertion, that is, to express that a state of affairs is true for a topic. For example, in a sentence such as 'The book was on the table' the copula expresses that 'being on the table' was true of the book (cf. Klein 1994 for a detailed discussion of these ideas). Consequently, when learners acquire finiteness, the assertion function that was previously fulfilled by the linking elements is taken over by finiteness marking on verbs. From this moment on, L2 learners of German and Dutch start to produce utterances of the following type, in which a finite verb - in this case an auxiliary verb - occupies the position that was formerly reserved for linking elements:

$$
\begin{aligned}
& \text { Ik heb niet zeggen. } \\
& \text { I have not say } \\
& \text { 'I have not said.' (Jordens and Dimroth 2006: 186) }
\end{aligned}
$$

In summary, the results from Jordens and Dimroth's study show that learners who have not yet acquired finiteness marking produce utterances that consist of the following (optional) elements: topic, linking element, and predicate. After learners acquire finiteness marking, their utterances typically contain a subject, finite verb and one or more arguments. Importantly, the function of finiteness marking (assertion) is then fulfilled by finite verbs and the elements that previously functioned as linking elements such as niet appear behind the verb.

\subsection{Different functions of TAPs and TACs}

The linking elements that Jordens and Dimroth list in their study are the following:

- modal verbs (wil 'want')

- light verbs (doetie 'does-it') 
- adverb-like elements (nee 'no', ja 'yes')

- modal particles (eve 'just')

- scope particles (ook 'also')

Crucially however, the data presented in the current study suggest that TACs can also serve this linking function in L2 Dutch. For L2 German, such a tentative claim has been made by Dimroth et al. (2003) who noted that the scope particles noch 'still' and wieder 'again' function as linking elements. Dimroth et al. give the following example for wieder being used as a linking element by a learner of German:

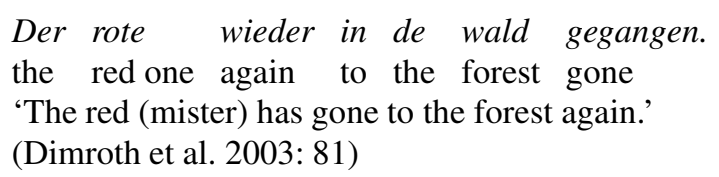

For L2 Dutch, only the scope particle ook 'also' has been assumed to fulfill this function. However, there is evidence in the literature that scope particles (including the temporal particles or TACs as we have termed them here) interact with finiteness. Dimroth (2002) observed, for example, that L2 learners of German used the particles auch 'also', noch 'still' and wieder 'again' in complementary distribution with auxiliary verbs. Moreover, Schimke et al. (2008) observed that L2 learners of German and Dutch typically use non-finite verbs in utterances with the particles auch/ook 'also' and wieder/weer 'again' whereas they tend to use finite verbs in similar utterances without those particles. Hence, there seems to be an interaction between the presence of such particles and the marking of finiteness in L2 German and Dutch.

To account for this interaction, we have to consider the function of particles that apply to time spans, or TACs as they are termed in the present paper. As argued above, adverbials such as 'still' and 'again' relate to two time intervals, one that is marked by the current sentence and another one that is implied. Consider the utterance in (31) where 'still' marks that the current state of affairs (John is sleeping) is true in addition to one or more earlier (continuative) time intervals or topic times at which John was sleeping. Similarly, note that in (32), the adverbial 'again' marks that John is sleeping in addition to a non-adjacent earlier time interval.

John is still asleep.

$$
\text { John is asleep again. }
$$

Since 'still' and 'again' assert that something is true at a particular topic time in addition to an (adjacent or non-adjacent) earlier topic time, it has been argued that they mark 'repeated assertions' (Dimroth 2002). Relating this to the idea that finiteness marks assertion, it is clear that the functions of TACs and 


\subsection{Fronted adverbials}

Another indication that TAPs mark the topic time and occur in the topic component while TACs function as linking elements is that TAPs more often occur in sentence-initial position than TACs. From the double-adverbial constructions, it had already become clear that TAPs occurred in initial position, but it appears that this pattern also holds when utterances are considered that contain only one adverbial. Table 4 presents for all adverbials that occurred in initial position (i.e., fronted adverbials such as $\mathrm{Nu}$ hij gooit de bal 'Now he throws the ball') whether it involved a TAP or TAC. For this analysis, all utterances were considered in which an adverbial occurred in sentence-initial position and an overt subject followed this adverbial. Note that these utterances were excluded for the previous analyses where only utterances of the type Hij nu gooit de bal 'He now throws the ball' were considered, with an adverbial occurring in between the subject and the verb.

Clearly, the vast majority of adverbials that occur in initial position are TAPs: $90 \%$ and $88 \%$ for the Moroccan and Turkish learners, respectively. ${ }^{16}$ The following utterances illustrate this:

$$
\begin{aligned}
& \mathrm{Nu} \text { meisjes ligt de gebak op de tafel. } \\
& \text { now girl lies the cake on the table } \\
& \text { 'Now the girl is putting the cake on the table.' }
\end{aligned}
$$

$$
\begin{aligned}
& \text { Eerst hij zien van de politie. } \\
& \text { first he looks of the police officer } \\
& \text { 'First, he is looking at the police officer.' }
\end{aligned}
$$

The finding that sentence-initial adverbials occur more often TAPs than TACs provides further support for the idea that TAPs are in topic position but TACs are not (but instead, occur sentence-medially) in early L2 Dutch.

\subsection{Interaction with finiteness marking}

The third finding that supports the idea of TAPs as markers of the topic time and TACs as linking elements involves finiteness marking. As we have seen, Jordens and Dimroth claimed that finite verbs take over the function of linking

16. An anonymous reviewer asks whether the relatively high number of fronted adverbials could reflect a meta-linguistic mechanism that is used (especially by low proficient L2 learners) to avoid mistakes if they are unsure where to put an adverbial within the sentence. However, such a strategy does not seem likely given that the learners seemed to monitor their own speech for semantic distinctions such as correct personal pronouns ('he' vs. 'she') rather than syntactic ones, as evidenced by their hesitations and self-corrections. 
Table 4. Adverbials in sentence-initial position

\begin{tabular}{lccccc}
\hline & \multicolumn{2}{c}{ Moroccan learners } & & \multicolumn{2}{c}{ Turkish learners } \\
\cline { 2 - 3 } \cline { 6 - 6 } & $\%$ & & & $\%$ & $\mathrm{~N}$ \\
\hline TAP & 90 & $(56)$ & & 88 & $(58)$ \\
TAC & 10 & $(6)$ & & 12 & $(8)$ \\
\hline
\end{tabular}

elements as soon as learners acquire finiteness. Therefore, we can predict that when a finite verb is placed in linking position, TACs and negation follow this finite verb. However, when TACs and negation occupy the linking slot, verbs are expected to be unmarked for finiteness. No such relation is expected for TAPs: such adverbials occur in the topic component and do not serve the same (assertion) function as finiteness.

To test the idea that there is an interaction between TACs and negation on the one hand and finiteness marking on the other, all verbs that co-occurred with adverbials and niet were analyzed for (i) whether the adverbial or negator preceded or followed the verb and (ii) whether the verb was finite or non-finite. Only 3sg-contexts were taken into account and finiteness was defined as correct subject-verb agreement. Hence, verb forms ending in a correct 3 sg-suffix ( ' $-t$ ') as in (38) were considered finite while those in (39) and (40) were considered non-finite.

$$
\begin{aligned}
& \text { De bal blijft weer op de boom. } \\
& \text { the ball stay-3sg again (=still) on the tree } \\
& \text { 'The ball still stays in the tree.' }
\end{aligned}
$$

$$
\begin{aligned}
& \text { En de bal blijf nog steeds in de boom. } \\
& \text { and the ball stay-1sg.0 still } \\
& \text { 'And the ball still stays in the tree.' }
\end{aligned}
$$

$$
\begin{aligned}
& \text { Dief nog steeds binnen blijven. } \\
& \text { thief still inside stay-inf.pl } \\
& \text { 'The thief still stays inside.' }
\end{aligned}
$$

Table 5 presents how often verbs were correctly marked for finiteness in sentences containing TAPs, TACs, and niet.

The data show that the Moroccan learners marked finiteness on $74 \%$ of all verbs that occurred with a post-verbal TAC but on only $17 \%$ of all verbs that occurred with a pre-verbal TAC. A similar pattern was found for the Turkish learners (71\% vs. $12 \%)$. For both language groups, these differences are significant $\left(\chi^{2}(1)=6.117, p=.023\right.$ for the Moroccans; $\chi^{2}(1)=14.263, p<.001$ for the Turks). Hence, there is a significant interaction between the placement 
Table 5. Finiteness marking in relation to the positioning of TAPs, TACs and negation

\begin{tabular}{|c|c|c|c|c|c|c|c|c|c|c|}
\hline & \multicolumn{5}{|c|}{ Moroccan learners } & \multicolumn{5}{|c|}{ Turkish learners } \\
\hline & \multicolumn{2}{|c|}{ Pre-verbal } & \multicolumn{2}{|c|}{ Post-verbal } & \multirow[t]{2}{*}{ Total } & \multicolumn{2}{|c|}{ Pre-verbal } & \multicolumn{2}{|c|}{ Post-verbal } & \multirow[t]{2}{*}{ Total } \\
\hline & $\%$ & $\mathrm{~N}$ & $\%$ & $\mathrm{~N}$ & & $\%$ & $\mathrm{~N}$ & $\%$ & $\mathrm{~N}$ & \\
\hline TAP & 50 & $(6 / 12)$ & 33 & $(1 / 3)$ & 15 & 10 & $(3 / 30)$ & 50 & $(4 / 8)$ & 38 \\
\hline TAC & 17 & $(1 / 6)$ & 74 & $(14 / 19)$ & 25 & 12 & $(3 / 25)$ & 71 & $(10 / 14)$ & 39 \\
\hline NEG & - & $(0 / 7)$ & 88 & $(22 / 25)$ & 32 & - & $(0 / 10)$ & 78 & $(7 / 9)$ & 19 \\
\hline
\end{tabular}

of a TAC with respect to the verb and the presence of finiteness marking on this verb: verbs that are followed by a TAC are significantly more often finite than verbs that are preceded by a TAC. The following examples illustrate this pattern with utterances containing the verb staan 'stand':

$$
\begin{aligned}
& \text { De bal nog staan op de boom. } \\
& \text { the ball still stand-inf.pl on the tree } \\
& \text { 'The ball is still hanging in the tree.' }
\end{aligned}
$$

$$
\begin{aligned}
& \text { Die bal staat nog op de boom. } \\
& \text { the ball stand-3sg still on the tree } \\
& \text { 'The ball is still hanging in the tree.' }
\end{aligned}
$$

When we look at the data for negation, it appears that the pattern is even clearer: not a single utterance was found in which the negator preceded a finite verb. For both language groups, the differences are highly significant $\left(\chi^{2}(1)=21.403\right.$, $p<.001, \chi^{2}(1)=15.473, p=.001$, for the Moroccan and Turkish learners respectively): verbs that occur with post-verbal negation are significantly more often finite than verbs that occur with pre-verbal negation. The following examples again illustrate this with utterances that contain the same verb:

$$
\begin{aligned}
& \text { Die man niet pakken de brood. } \\
& \text { the man not take-inf.pl the bread } \\
& \text { 'The man does not take the bread.' }
\end{aligned}
$$

$$
\begin{aligned}
& \text { Hij pakt niet de bal. } \\
& \text { he take-3sg not the ball } \\
& \text { 'He does not take the ball.' }
\end{aligned}
$$

Finally, when we look at the distribution of finite and non-finite verbs over contexts with TAPs, a different pattern arises, at least for the Moroccan learners. These learners even show the opposite pattern: verbs that occur with pre-verbal TAPs are more often finite than verbs that occur with post-verbal TAPs, but since the number of post-verbal occurrences is low, no firm conclusions can be 
drawn. However, the Turkish learners do show the same pattern as for TACs and negation. A chi-square analysis reveals that the difference is significant $\left(\chi^{2}(1)=5.711, p=.025\right)$. Albeit significant, however, this pattern is less clear than for TACs and for negation.

In summary, the results support the idea that there is a relation between finiteness marking and the placement of TACs and negation in the sense that TACs tend to precede non-finite but follow finite verbs. For TAPs, such an interaction is less clear: for the Moroccan learners, the data show the reversed pattern while for the Turkish learners, the interaction is present but weaker than for TACs and negation.

\section{Conclusion and discussion}

This paper started out with two questions: (i) Can the finding that adverbial placement is acquired after negation placement be confirmed for L2 Dutch and if so, (ii) How should this finding be explained? Concentrating on temporal adverbials, the results showed that adverbials are indeed more often found in pre-verbal position than negation. However, when a distinction was made between different types of adverbials (TAPs versus TACs), it appeared that TAPs do not pattern like negation, whereas TACs do. TAPs indicate the time span for which a specific claim is made and therefore typically occur in the topic part of utterances at early stages of acquisition. TACs and negation, on the other hand, link a predicate (or rather: the state of affairs expressed by this predicate) to a topic. As such, they express a similar function in the sense that they assert that a state of affairs holds for a topic, in the case of TACs this assertion being made for the current time in addition to an earlier topic time. Negation expresses that a state of affairs is not true of the topic and therefore also comes close to this assertion function. As long as finiteness is not marked by L2 learners both TACs and TAPs occur in pre-verbal position. At a deeper level, however, TAPs belong to the topic part, while TACs fill the slot that is used for elements that mark finiteness. When finiteness marking on verbs is acquired, the positional differences between TAPs and TACs become more visible: TAPs remain in pre-verbal position while TACs occur in post-verbal position when finite verbs occupy the position for finite elements.

Relating this to the explanations that were proposed by Hawkins et al. (1993) and Herschensohn (1998), it is not immediately clear how the current results would fit these ideas. First, the idea that learners apply a specific UG mechanism to acquire negation placement and another UG mechanism to acquire adverbial placement is difficult to reconcile with the finding that adverbials of contrast pattern exactly like negation. As for Herschensohn's idea that parameter setting is based on the acquisition of specific lexical items, the results are 
even less supportive. Namely, according to this view, one would expect to find variation within one class of adverbials in the sense that a given TAC, for example 'still', might behave differently from another type of TAC, for example, 'again'. However, this is not in line with the current findings. Clearly however, it is difficult to draw a direct comparison between the present results and those from Hawkins et al. (1993) and Herschensohn (1998). First, the learners in the current study were certainly less advanced and therefore, the different results might also be due to differences in proficiency level across studies. Second, and more importantly, the current learners barely produced TAFs, the type of adverbial investigated by Hawkins et al. (1993) and Herschensohn (1998). Therefore, a direct comparison of the results is not without problems.

As for the possible role of the L1, the data showed that the Moroccan and Turkish learners showed the same patterns but that the tendencies were clearest for the Moroccans. Moreover, different overall preferences were found for the two language groups: while the Moroccan learners had an overall preference for post-verbal placement, the Turkish group preferred pre-verbal placement, both with negation and adverbials. This difference is not surprising in light of the fact that Moroccan Arabic has verb-raising, but Turkish has not. What is interesting, then, is that the fact whether or not a language has verb-raising seems to be more important than the exact position of negation and adverbials in this language. More precisely, the Moroccan learners had a preference for post-verbal negation despite the fact that Moroccan Arabic marks negation with a circumfix, of which the pre-verbal affix is obligatory but the suffix is not (i.e, negation is often expressed by a prefix only and hence, pre-verbal). Second, the Turkish learners generally preferred pre-verbal negation whereas Turkish marks negation post-verbally, with a suffix. Thus, it seems that the presence versus absence of verb-raising in a learner's native language is more decisive for the learner's acquisition of post-verbal adverbial and negation placement in the L2 than the exact position adverbials and negation occupy with respect to the finite verb in the L1.

Finally, it is worth pointing out that the utterances that were produced by the L2 learners are not assumed to be unique for L2 acquisition. Rather, native speakers are expected to display the same preferences when they speak their native language. In the target language, TAPs are suitable markers of the topic time and thus likely to occur in topic position, while TACs link a state of affairs to previous topic times and hence, are likely to be embedded in the focus part of the sentence. What is unique for L2 acquisition, then, is the interaction with finiteness marking that causes the pre-verbal placement of TAPs, on the one hand, and the post-verbal placement of TACs and negation, on the other.

Still, it is interesting to test to what extent native speaker data reflect the same distributions as the L2 data. Therefore, the data of ten Dutch native speakers, who performed the same film-retelling task and two out of the three picture 
Table 6. Adverbial placement in Dutch native speakers

\begin{tabular}{|c|c|c|c|c|c|}
\hline & \multicolumn{2}{|c|}{ Sentence-initial } & \multicolumn{2}{|c|}{ Post-verbal } & \multirow[t]{2}{*}{ Total } \\
\hline & $\%$ & $\mathrm{~N}$ & $\%$ & $\mathrm{~N}$ & \\
\hline TAP & 74 & (42) & 26 & (15) & 57 \\
\hline TAD & - & (0) & 100 & (3) & 3 \\
\hline TAF & 20 & (1) & 80 & (4) & 5 \\
\hline TAC & - & (0) & 100 & (81) & 81 \\
\hline
\end{tabular}

stories as the L2 learners, were analysed. ${ }^{17}$ Table 6 presents the results. It indicates for all four types of adverbial how often adverbials occurred in sentenceinitial or post-verbal position (these being the only positions in which temporal adverbials were found).

The data show clear distributional differences between TAPs and TACs TAPs are predominantly placed in sentence-initial position ( $74 \%$ vs. $26 \%$ ) but TACs never occur in this position. The absence of TACs in initial position is remarkable because the fronting of adverbials is grammatical in Dutch. ${ }^{18}$ In interpreting the above data, however, one should keep in mind that the data are taken from narrative data only and that they were collected from a relatively small group of speakers. Nevertheless, they show that the same preferences are found in native speakers and L2 learners. This entails that it is hard to disentangle the influence of scope marking and input patterns in the L2 data. However, the idea that scope marking is of influence rather than input patterns alone, receives support from the finding that the placement of TACs and negation interacts with finiteness, but the placement of TAPs does not (or less so). Moreover, the data in Table 6 show that the native speakers did not produce many TADs and TAFs. Since the same was found for the L2 learners, this suggests that the low number of such adverbials in the data was due to the task rather than to these adverbials being acquired late in acquisition. ${ }^{19}$

Altogether, the results of the study show that adverbials might be a too diverse class to be directly compared against negation. Moreover, the present

17. These participants also had a relatively low level of schooling and were tested at the same type of schools as the learners (i.e., Dutch Regionaal Opleidingen Centrum - Regional Education Centre), where they received professional training, for example, to become an assistant in a shop. However, unlike the L2 learners, all control speakers had finished primary school and in addition, they had spent four years at secondary (low-level, vocational) education.

18. Examples are Weer gaat hij naar buiten 'Again goes he outside' and Nog steeds ben ik moe 'Still am I tired'.

19. Unfortunately, since it was not foreseen that learners would differentiate between different types of adverbial, previous task piloting was not directed towards eliciting different temporal adverbials but rather, at the use of adverbials in general. 


\section{Josje Verhagen}

findings suggest that a purely syntactic approach cannot satisfactorily explain the L2 acquisition of adverbial and negation placement, at least not at relatively early stages of acquisition. Rather, a closer look into different types of adverbials' scope properties as well as their interaction with finiteness marking seems to explain why TACs behave like negation in L2 acquisition but TAPs do not.

\section{Max Planck Institute for Psycholinguistics $<$ Josje.Verhagen@mpi.nl>}

\section{References}

Becker, Angelika (2005). The semantic knowledge base for the acquisition of negation and the acquisition of finiteness. In The Structure of Learner Varieties, Henriette Hendriks (ed.), 263314. Berlin/New York: Mouton de Gruyter.

Bernini, Giuliano (2003). The copula in learner Italian: Finiteness and verbal inflection. In Information Structure and the Dynamics of Language Acquisition, Christine Dimroth and Marianne Starren (eds.), 159-185. Amsterdam: John Benjamins.

Chomsky, Noam (1995). The Minimalist Program. Cambridge, MA: MIT Press.

Clahsen, Harald (1980). Psycholinguistic aspects of L2 acquisition: Word order phenomena in foreign workers' interlanguage. In Second Language Development: Trends and Issues, Sascha W. Felix (ed.), 57-80. Tübingen: Narr.

Clahsen, Harald, Jürgen Meisel and Manfred Pienemann (1983). Deutsch als Zweitsprache: Der Spracherwerb Ausländischer Arbeiter. Tübingen: Narr.

Council of Europe (2001). A Common European Framework of Reference for Languages: Learning, Teaching, Assessment. Cambridge: Cambridge University Press.

Dietrich, Reiner, Wolfgang Klein and Colette Noyau (1995). The Acquisition of Temporality in a Second Language. Studies in Bilingualism 7. Amsterdam: John Benjamins

Dimroth, Christine (2002). Topics, assertions and additive words: How L2 learners get from information structure to target-language syntax. Linguistics 40 (2): 891-923.

Dimroth, Christine, Petra Gretsch, Peter Jordens, Clive Perdue and Marianne Starren (2003). Finiteness in Germanic languages. In Information Structure and the Dynamics of Language Acquisition, Christine Dimroth and Marianne Starren (eds.), 65-93. Amsterdam: John Benjamins.

Erguvanl1, Eser E. (1984). The Function of Word order in Turkish Grammar. Berkeley: University of California Press.

Eubank, Lynn (1992). Verb movement, agreement and tense in L2 acquisition. In The Acquisition of Verb Placement: Functional Categories and V2 Phenomena in Language Acquisition, Jürgen Meisel (ed.), 225-244. Dordrecht: Kluwer.

Giuliano, Patrizia (2003). Negation and relational predicates in French and English as second languages. In Information Structure and the Dynamics of Language Acquisition, Christine Dimroth and Marianne Starren (eds.), 119-157. Amsterdam: John Benjamins.

Harrell, Richard S. (1962). A Short Reference Grammar of Moroccan Arabic. Washington: Georgetown University Press.

Hawkins, Roger, Richard Towell and Nives Bazergui (1993). Universal Grammar and the acquisition of French verb movement by native speakers of English. Second Language Research 9 (3): 189-233. 
Haznedar, B. (1997). L2 acquisition by a Turkish speaking child: Evidence for L1 influence. In Proceedings of the 21st Annual Boston Conference on Language Development, Mary Hughes and Annabel Greenhill (eds.), 245-256. Somerville, MA: Cascadilla Press.

Herschensohn, Julia (1998). Minimally raising the verb issue. In Proceedings of the 22nd Annual Boston Conference on Language Development, Annabel Greenhill, Mary Hughes, Heather Littlefield and Hugh Walsh (eds.), 325-336. Somerville, MA: Cascadilla Press.

Holes, Clive (1995). Modern Arabic: Structures, Functions and Varieties. New York: Longman. Jordens, Peter and Christine Dimroth (2006). Finiteness in children and adults learning Dutch. In The Acquisition of Verbs and their Grammar, Natalia Gagarina and Insa Gülzow (eds.), 173-200. Dordrecht: Springer.

Klein, Wolfgang and Clive Perdue (1997). The basic variety (or: couldn't natural languages be much simpler?). Second Language Research 13 (4): 301-347.

Klein, Wolfgang (1994). Time in Language. London: Routledge.

Kornfilt, Jaklin (1997). Turkish. London: Routledge.

Meisel, Jürgen, Harald Clahsen and Manfred Pienemann (1981). On determining developmental stages in natural second language acquisition. Studies in Second Language Acquisition 3 (2): 109-135.

Ouhalla, Jamal (1991). Functional Categories and Parametric Variation. London: Routledge.

Ouali, Hamid and Catherine Fortin (2007). The syntax of complex tense in Moroccan Arabic. In Perspectives on Arabic linguistics XIV, Elabbas Benmamoun (ed.), 175-189. Amsterdam: John Benjamins.

Pollock, Jean-Yves (1989). Verb movement, Universal Grammar, and the structure of IP. Linguistic Inquiry 20 (3): 365-424.

Rizzi, Luigi (1990). Relativised Minimality. Cambridge, MA: MIT Press.

Schimke, Sarah, Josje Verhagen and Christine Dimroth (2008). Particules additives et finitude en néerlandais et allemand L2: Une étude experimentale. Acquisition et Interaction en Language Etrangère (AILE) 27.

Starren, Marianne and Roelant van Hout (1996). Temporality in learner discourse: What temporal adverbials can and what they cannot express. Zeitschrift für Literaturwissenschaft und Linguistik 104: 35-50.

Starren, Marianne (2001). The second time: The acquisition of temporality in Dutch and French as a second language. Unpublished doctoral dissertation, University of Tilburg, the Netherlands. 